\title{
PENDIDIKAN KESEHATAN TENTANG SENAM DISMENORE UNTUK MENURUNKAN DISMENORE PADA REMAJA
}

\section{"HEALTH EDUCATION ABOUT DYSMENORRHEA EXERCISES TO REDUCE DYSMENORRHEA IN ADOLESCENTS"}

\author{
Rodiyah, Erika Agung Mulyaningsih \\ Stikes Pemkab Jombang \\ Email : azizdanahsan@gmail.com
}

\begin{abstract}
ABSTRAK
Pada saat menstruasi beberapa remaja mengalami dismenore. Dismenore didefinisikan sebagai nyeri uterus yang bersifat siklik yang terjadi sebelum atau selama menstruasi. Remaja biasanya menggunakan minum air hangat, mengompres perut dengan botol yang diisi air hangat, minum jamu atau obat pengurang nyeri, memberikan minyak kayu putih, melakukan nafas dalam, diperiksakan ke petugas kesehatan bahkan ada yang dibiarkan saja. Tujuan pengabdian masyarakat ini adalah memberikan alternatif untuk penatalaksaan dismenore pada remaja. Metode yang digunakan adalah dengan memberikan pendidikan kesehatan dengan media zoom. Hasil yang didapatkan setelah dilakukan pemberian pendidikan kesehatan hampir seluruhnya mahasiswi tahu tehnik non farmakologis untuk mengurangi dismenore. Senam dismenore adalah salah satu tehnik non farmakologis untuk mengurangi nyeri. Senam ini banyak keuntungannya karena selain murah juga bisa dilakukan sendiri oleh mahasiswi. Diharapkan mahasiswi bisa mengaplikasikannya ketika mengalami dismenore.
\end{abstract}

Kata Kunci: Senam Dismenore, Dismenore, Remaja

\begin{abstract}
Some teenagers experience dysmenorrhea during menstruation. Dysmenorrhea defined as uterine pain of a cyclic nature that occurs before or during menstruation. Teenagers usually drink warm water, compress the stomach with a bottle filled of warm water, drink herbs or painrelieving drugs, give eucalyptus oil, do deep breaths, check to health workers and some are even left alone. The purpose of this community service is to provide an alternative for the management of dysmenorrhea in adolescents. The method used to provide health education using online meeting. The results obtained after providing health education were almost all female students who knew non-pharmacological techniques to reduce dysmenorrhea. Dysmenorrhea exercise is one of the non-pharmacological techniques to reduce pain. This exercises has many advantages because it is cheap, it can also be done by students. It is expected that female students can apply when experiencing dysmenorrhea.
\end{abstract}

Keywords : Dysmenorrhea Exercises, Dysmenorrhea, Adolescents

\section{PENDAHULUAN}

Remaja dapat di definisikan sebagai

individu yang berusia $11-12$ tahun sampai 20 -21 tahun. Remaja merupakan individu

yang mengalami perubahan pada penampilan fisik maupun perubahan psikologis. Remaja merupakan masa penting 
dalam perjalanan kehidupan manusia. Masa remaja ini merupakan jembatan antara masa kanak- kanan yang bebas menuju masa dewasa yang menuntut tanggung jawab (Kusmiran 2011).

Menstruasi adalah pengeluaran darah yang terjadi karena adanya perubahan hormon yang terus menerus dan mengarah pada pembentukan endometrium, ovulasi sehingga mengakibatkan terjadinya peluruhan dinding rahim jika tidak terjadi kehamilan ( Verawaty, 2012).

Banyak remaja ketika menstruasi mengalami keluhan salah satunya yang paling sering dilaporkan adalah nyeri menstruasi atau dismenore. Pada saat mengalami dismenore wanita biasanya mengalami kram bagian bawah perut yang menjalar ke punggung atau kaki dan biasanya disertai gejala gastrointestinal dan gejala neurologis seperti kelemahan umum sehingga banyak remaja yang akhirnya mereka membutuhkan istirahat sehingga mengakibatkan berkurangnya aktiitas seharihari.

Tiga tahun pertama setelah menarche remaja biasanya mengalami dismenore. Wanita dewasa muda usia 17-24 tahun adalah kelompok usia yang paling sering melaporkan menstruasi dengan disertai nyeri (Lowdermilk, 2013).

Dismenore yaitu nyeri menstruasi yang di rasakan sebagai nyeri yang singkat sebelum atau selama menstruasi (Reeder 2013).

Penelitian di Indonesia menyatakan bahwa prevalensi dismenore yaitu $64,25 \%$ yang terdiri dari $54,89 \%$ sebagai dismenore primer dan 9,36\% sebagai dismenore sekunder ( Bahri ,2015)
Studi pendahuluan yang dilakukan pada remaja didapatkan hasil bahwa selama mereka menderita dismenore mereka biasanya sulit untuk berkonsentrasi, malas dan tidak bisa melakukan aktivitas kerena menahan nyeri. Bebarapa hal yang biasanya dilakukan oleh remaja adalah minum air hangat, mengompres perut dengan botol yang diisi air hangat, minum jamu atau obat pengurang nyeri, memberikan minyak kayu putih, melakukan nafas dalam, diperiksakan ke petugas kesehatan bahkan ada yang dibiarkan saja.

Senam dismenore merupakan aktivitas fisik yang dapat digunakan untuk mengurangi dismenore. Saat melakukan gerakan senam, tubuh akan menghasilkan hormone endorphin. semakin tinggi hormon ini akan menurunkan nyeri yang dirasakan seseorang sehingga menjadi lebih nyaman, gembira, oksigen juga akan lancar ke otot (Sugani, 2010).

Senam juga menjadi salah satu teknik relaksasi yang bisa digunakan untuk mengurangi nyeri karena saat melakukan senam, otak dan susunan saraf tulang belakang akan menghasilkan hormon endorphin, fungsi hormon ini adalah sebagai obat penenang alami dan menimbulkan rasa nyaman (Marlinda \& Purwaningsih, 2013)

Meskipun dismenore menjadi masalah pada remaja tapi banyak remaja yang membiarkan saja tanpa melakukan tindakan untuk mengatasi nyeri. Mengingat hal tersebut, maka dosen STIKES Pemkab Jombang ingin mengadakan kegiatan pengabdian masyarakat dengan judul "Pendidikan Kesehatan Tentang Senam Dismenore Untuk Menurunkan Dismenore Pada Remaja" 


\section{METODE PELAKSANAAN}

Kegiatan pengabdian masyarakat dengan ini di lakukan tanggal 7 September 2021 pada mahasiwi sarjana keperawatan tingkat 2 semester 3 Kegiatan ini bertujuan untuk meningkatka pengetahuan mahasiswi tentang tehnik mengurangi dismenore salah satunya dengan senam dismenorea. Sebelum melakukan kegiatan pengabdian masyarakat ini tim pelaksana melakukan ijin kepada ketua stikes dan ketua program studi sarjana keperawatan, Pengabdian masyarakat ini dilakukan melalui media zoom.

Kegiatan inti:

1. Dilakukan pembukaan oleh ketua Program studi

2. Mengidentiikasi pengetahuan dan pemahaman mahasiswi tentang dismenore, cara mengatasi dismenore yang dilakukan oleh mahasiswi selama ini.

3. Pemberian materi tentang dismenore

4. Mahasiswi mencoba senam dismenore sendiri sendiri sesuai dengan panduan yang ada di leaflet

5. Tanya jawab tentang dismenore dan senam dismenore

\section{Kegiatan penutup.}

1. Mengulang kembali penyuluhan tentang dismenore dan senam dismenore.

2. Menyarankan mahasiswi untuk mempraktekkan senam dismenore sebagai salah satu upaya terapi non farmakologi untuk menurunkan dismenore.

\section{HASIL DAN PEMBAHASAN}

Kegiatan pengabdian masyarakat ini dilaksanakan melalui apllikasi Zoom yang dikuti oleh 50 mahasiswi .
Sasaran pengabdian masyarakat ini adalah mahasiswi dengan usia antara $18 \mathrm{~s} / \mathrm{d}$ 20 tahun.

Pelaksanaan pengabdian masyarakat ini berjalan lancar walaupun dilakukan dengan media zoom dikarenakan masih dalam masa pandemic covid 19

Pada kegiatan ini mahasiswi sangat antusias terbukti dengan banyaknya pertanyaan yang masuk pada sesi Tanya jawab karena selama ini mahasiswi banyak yang belum tahu tentang penatalaksanaan dismenore, selama ini mereka sering melakukan beberapa penatalaksaan untuk mengurangi nyeri salah satunya adalah minum air hangat, mengompres perut dengan botol yang diisi air hangat, minum jamu atau obat pengurang nyeri, memberikan minyak kayu putih, melakukan nafas dalam, diperiksakan ke petugas kesehatan karena sudah tidak bisa menahan nyeri, bahkan ada yang dibiarkan saja.

Dimenorea bisa diatasi salah satunya dengan pengunaan terapi non farmakologi yang tidak menimbulkan efek samping. Terapi non farmakologi ini selain mudah juga tidak membutuhkan biaya selain itu juga bisa dilakukan secara mandiri oleh mahasiswa. Terapi non farmakologi juga bisa dilakukan untuk mengurangi dismenore tetapi hal tersebut akan menjadi sebuah ketergantungan dan menimbulkan efek samping yang tidak diinginkan.

Dari hasil pelaksanaan pengabdian masyarakat ini di harapkan mahasiswa bisa mengaplikasikan senam dismenore. Senam ini sesuai dengan teori bisa dilaksanakan sebelum siklus menstruasi bulan selanjutnya atau saat menstruasi hari pertama ( selama 2-3 kali dalam seminggu) 


\section{DAFTAR PUSTAKA}

1. Bahri, A. A., Afriwardi, \& Yusrawati. 2015. Hubungan antara Kebiasaan Olahraga dengan Dismenore pada Mahasiswi Pre-Klinik Program Studi Pendidikan Dokter Fakultas Kedokteran Universitas Andalas Tahun Ajaran 2012-2013. Jurnal Kesehatan Andalas, 4(3); p.815-821

2. Kusmiran, E. 2011. Kesehatan Reproduksi Remaja dan Wanita. Jakarta : Salemba Medika.

3. Lowdermilk, D, Shannon, P, Mary, C.C, 2013, Keperawatan Maternitas, Ed. 8. Elsevier, Singapura

4. Marlinda, Rofli., Rosalina.,Purwaningsih, Puji. 2013.
Pengaruh Senam Dismenore Terhadap Penurunan Dismenore Pada Remaja Putri Di Desa Sidoharjo Kecamatan Pati. Jurnal keperawatan maternitas. Vol 1 NO.2. November 2013.

5. Verawaty, SN dan Liswidyawati, R. 2012. Merawat dan Menjaga Kesehatan Seksual Wanita. PT Grafindo Media Pratama. Bandung

6. Reeder, S. J., Martin, Griffin, K. 2013. Keperawatan Maternitas: Kesehatan Wanita, Bayi, dan Keluarga, Jakarta: EGC.

7. Sugani \& Priandarini, 2010, Cara cerdas untuk sehat : Rahasia hidup sehat tanpa dokter, Transmedia, Jakarta. 